\title{
Emergency Department-Based Brief Intervention to Reduce Risky Driving and Hazardous/Harmful Drinking in Young Adults: A Randomized Controlled Trial
}

\section{Citation}

Sommers, Marilyn S., Michael S. Lyons, Jamison D. Fargo, Benjamin D. Sommers, Catherine C. McDonald, Jean T. Shope, and Michael F. Fleming. 2013. "Emergency Department-Based Brief Intervention to Reduce Risky Driving and Hazardous/Harmful Drinking in Young Adults: A Randomized Controlled Trial." Alcohol Clin Exp Res 37 (10): 1753-1762. doi:10.1111/acer.12142.

\section{Published Version}

doi:10.1111/acer.12142

\section{Permanent link}

http://nrs.harvard.edu/urn-3:HUL.InstRepos:14008374

\section{Terms of Use}

This article was downloaded from Harvard University's DASH repository, and is made available under the terms and conditions applicable to Other Posted Material, as set forth at http:// nrs.harvard.edu/urn-3:HUL.InstRepos:dash.current.terms-of-use\#LAA

\section{Share Your Story}

The Harvard community has made this article openly available.

Please share how this access benefits you. Submit a story. 


\title{
Emergency Department-Based Brief Intervention to Reduce Risky Driving and Hazardous/Harmful Drinking in Young Adults: A Randomized Controlled Trial
}

\author{
Marilyn S. Sommers, Michael S. Lyons, Jamison D. Fargo, Benjamin D. Sommers, \\ Catherine C. McDonald, Jean T. Shope, and Michael F. Fleming \\ School of Nursing (MSS, CCM), University of Pennsylvania, Philadelphia, Pennsylvania; \\ Department of Emergency Medicine, College of Medicine (MSL), The University of Cincinnati, \\ Cincinnati, Ohio; Department of Psychology (JDF), Utah State University, Logan, Utah; \\ Department of Health Policy and Management, School of Public Health (BDS), Harvard \\ University, Cambridge, Massachusetts; University of Michigan Transportation Research Institute \\ (JTS), University of Michigan, Ann Arbor, Michigan; and Family and Community Medicine, \\ Feinberg School of Medicine (MFF), Northwestern University, Chicago, Illinois.
}

\begin{abstract}
Background-Risky driving and hazardous drinking are associated with significant human and economic costs. Brief interventions for more than one risky behavior have the potential to reduce health-compromising behaviors in populations with multiple risk-taking behaviors such as young adults. Emergency department (ED) visits provide a window of opportunity for interventions meant to reduce both risky driving and hazardous drinking.

Methods-We determined the efficacy of a Screening, Brief Intervention, and Referral to Treatment (SBIRT) protocol addressing risky driving and hazardous drinking. We used a randomized controlled trial design with follow-ups through 12 months. ED patients aged 18 to 44 who screened positive for both behaviors $(n=476)$ were randomized to brief intervention (BIG), contact control (CCG), or no-contact control (NCG) groups. The BIG $(n=150)$ received a 20minute assessment and two 20-minute interventions. The CCG $(n=162)$ received a 20-minute assessment at baseline and no intervention. The NCG $(n=164)$ were asked for contact information at baseline and had no assessment or intervention. Outcomes at 3, 6, 9, and 12 months were self-reported driving behaviors and alcohol consumption.
\end{abstract}

Results-Outcomes were significantly lower in BIG compared with CCG through 6 or 9 months, but not at 12 months: Safety belt use at 3 months (adjusted odds ratio [AOR], 0.22; 95\% confidence interval [CI], 0.08 to 0.65 ); 6 months (AOR, 0.13 ; $95 \%$ CI, 0.04 to 0.42 ); and 9 months (AOR, 0.18; 95\% CI, 0.06 to 0.56); binge drinking at 3 months (adjusted rate ratio [ARR] 0.84; $95 \% \mathrm{CI}, 0.74$ to 0.97 ) and 6 months (ARR, $0.81 ; 95 \% \mathrm{CI}, 0.67$ to 0.97 ); and $\geq 5$ standard drinks/d at 3 months (AOR, 0.43 ; 95\% CI, 0.20 to 0.91 ) and 6 months (AOR, $0.41 ; 95 \%$ CI, 0.17 to 0.98 ). No substantial differences were observed between BIG and NCG at 12 months.

Copyright (C) 2013 by the Research Society on Alcoholism.

Reprint requests: Marilyn S. Sommers, University of Pennsylvania, Fagin Hall, Philadelphia, PA 19104-4217; Tel.: 215-746-8320; Fax: 215-746-7417; ssommer@nursing.upenn.edu. 
Conclusions-Our findings indicate that SBIRT reduced risky driving and hazardous drinking in young adults, but its effects did not persist after 9 months. Future research should explore methods for extending the intervention effect.

\section{Keywords}

Brief Intervention; Hazardous Drinking; Risky Driving

YOUNG ADULTHOOD IS a time of risk of motor vehicle crashes (Park et al., 2006; Patil et al., 2006; WHO, 2009) and hazardous/harmful drinking (Bingham et al., 2005; Sloan et al., 2011). While these behaviors co-occur in the phenomenon of drinking-driving, they also occur individually and lead to considerable mortality and morbidity (Bingham et al., 2005; Naumann et al., 2010; WHO, 2009). Park and colleagues (2006) noted that healthcompromising behaviors during young adulthood have received little attention as compared with other periods of the life span. Thus, prevention programs to reduce motor vehiclerelated injury and hazardous drinking are needed to promote health and reduce costs in the young adult population (Sommers et al., 2011).

The Emergency department (ED) remains an important portal for health care in the United States regardless of insurance or ability to pay (Fields et al., 2001; Tang et al., 2010) and is a promising setting for intervention programs focused on young adults. Adults between the ages of 20 to 50 years old use the ED more frequently than other age groups, account for more than $30 \%$ of all ED visits in a given year, and represented more than 40 million visits in 2008 (CDC, 2012). ED-delivered brief interventions for more than 1 risky behavior have the potential to reduce health-compromising behaviors in populations with multiple risktaking behaviors such as young adults.

The concept of providing prevention services in the ED (Llovera et al., 2003; Rhodes et al., 2000) serves as the backdrop for a growing number of randomized controlled trials (RCTs) of Screening, Brief Intervention, and Referral to Treatment (SBIRT) for separate but cooccurring behaviors such as hazardous drinking and aggressive acts (Houry et al., 2011; Walton et al., 2008, 2010). Other authors call for trials to reduce co-occurring behaviors such as alcohol, tobacco use, and illicit drug/psychoactive prescription use (Blow et al., 2011). These trials use a model of young adulthood that reflects multiple, not single risks (Jiang et al., 2011). While the ED has been used as a setting for RCTs targeted to reduce alcohol-related injury (Blow et al., 2006; D'Onofrio et al., 2008, 2012; Longabaugh et al., 2001; Maio et al., 2005; Walton et al., 2010), seat belt use (Fernandez et al., 2009), and alcohol use/alcohol-impaired driving (Mello et al., 2008), to date, no SBIRT trial has been published that seeks to reduce both risky driving and hazardous drinking. In addition, the question of assessment reactivity (Does screening alone serve as an intervention or do ED patients require a full brief intervention to reduce health-compromising behaviors?) remains of interest to scientists studying behavioral interventions (Bernstein and Bernstein, 2008; MacCambridge, 2009).

We examined the efficacy of an SBIRT to reduce both risky driving and hazardous drinking among young adults visiting the ED. Participants were randomized to 3 conditions after they screened positive for both risky driving and hazardous drinking: brief intervention group 
(BIG; assessed at baseline and received SBIRT with follow-up at 3, 6, 9, and 12 months); contact control group (CCG; assessed at baseline but received no intervention with followup at 3, 6, 9, and 12 months); and no-contact control group (NCG; not assessed at baseline, received no intervention, interviewed at 12 -month follow-up only).

\section{MATERIALS AND METHODS}

The sample was composed of young adult patients at an urban, tertiary care, Level I Trauma Center ED in Cincinnati, Ohio. Study procedures were approved by the Institutional Review Board of the University of Cincinnati, a Certificate of Confidentiality was obtained from the Centers for Disease Control and Prevention, and the trial was registered with clinicaltrials.gov (Trial Registration: NCT00164294).

ED patients who presented with illnesses or injuries and admitted to the ED between 8 AM and 2 AM on randomly selected days underwent a 3-minute screen on driving behaviors, alcohol use, and other health topics. Participants were eligible for the RCT if they: (i) drove a motor vehicle $\geq 2 \mathrm{~d} / \mathrm{wk}$; (ii) screened positive on 2 risky driving and 2 hazardous drinking items in the 3-minute screen; and (iii) were 18 to 44 years old. Participants were excluded if they: (i) had no identifiable residence or contact phone number; (ii) were under arrest at the time of ED visit; (iii) were unable to participate in an English language screen due to language or cognitive barriers; (iv) were admitted to the hospital as an inpatient; or (v) had a history of daily alcohol use suggesting alcohol dependence on the Alcohol Use Disorders Identification Test (AUDIT; Reinert and Allen, 2007). Participants whose AUDIT results suggested possible dependence (score of $\geq 2$ on any or all of the 3 alcohol dependence items on the AUDIT) were excluded and referred for further assessment (Fleming et al., 1997). Recruitment and enrollment began in September 2004 and ended in September 2008. All state, police, and hospital records were obtained by December 2009. Data entry and analysis were completed by December 2011.

\section{Initial Screening Procedures for Trial Inclusion}

On screening days, all patients were approached by study-trained research assistants in the ED for a brief, 3-minute eligibility screen for risky driving behaviors and alcohol consumption. To be eligible for enrollment, participants needed to screen positive for 2 risky driving outcomes and 2 hazardous drinking outcomes. We set the both risky driving and hazardous drinking cut-points for inclusion in the study through fitting a latent class cluster analysis on 790 screens of young adults in the ED.

Criteria for a positive risky driving screen (at least 2 of the following) included the following behaviors in the past month: (i) $\geq 2$ instances of driving 20 miles per hour (mph) over the speed limit; (ii) $\geq 2$ instances of driving through a yellow light as it changed to red; and (iii) wearing a safety belt only some of the time or never. Brief screening items for risky driving were chosen through consultation with experts at the University of Michigan Transportation Research Institute (Eby and Vivoda, 2003; Eby et al., 2000; Shope and Bingham, 2002). We considered hazardous drinking as alcohol consumption exceeding dietary guidelines: for males up to 14 drinks/wk and no more than 4 on drinking days, and for nonpregnant females up to 7 drinks/wk and no more than 3 on drinking days (NIAAA, 
2011; Stewart et al., 2010). To avoid the floor effect in the sample, the alcohol cut-points indicated drinking above hazardous drinking levels. Our alcohol cut-points for study inclusion (at least 2 of the following in the past month) were: (i) $\geq 4$ standard alcoholic drinks on a typical drinking day; (ii) $\geq 5$ drinks/occasion for women and $\geq 6$ for men; and (iii) $\geq 11 \mathrm{drinks} / \mathrm{wk}$ for women and $\geq 14$ for men.

\section{Randomization Procedures}

Prior to study initiation, a list of 550 participant numbers was randomized by computer software into 3 groups (BIG, CCG, NCG). Enrollment packets of the same size and thickness were placed in opaque envelopes, sealed, and locked in a drawer at the study site in consecutive order by participant number. In addition to SBIRT materials, a card in each packet indicated random assignment to group.

\section{Baseline Interview Procedures}

After participants provided consent, study staff selected the next consecutively numbered enrollment packet to determine the randomly assigned group. Participants randomized to the BIG and CCG received a 20-minute interview based on Fleming's Trial for Early Alcohol Treatment (TrEAT) protocol (Fleming et al., 1997; Sommers et al., 2006) along with questions on risky driving from Donovan's Driving Behavior Inventory (DDBI; Donovan, 1993; Shope and Bingham, 2002) and Eby and colleagues (Eby and Vivoda, 2003; Eby et al., 2000; see Outcome Measures below for details on instruments). Additional questions measured self-reported traffic crashes. Participants randomized to the NCG were asked for contact information only and were not interviewed. All participants received $\$ 20$ at the time of enrollment.

\section{The Intervention}

Participants in the BIG received two 20-minute patient-centered interventions, 1 face-to-face intervention in the ED, and a second telephone intervention 10 to 14 days after discharge. We included a booster intervention based on Longabaugh and colleagues' (2001) work, but rather than an in-person booster, we used a telephone booster intervention (D'Onofrio et al., 2012; Sommers et al., 2006). In the ED-based intervention, driving behaviors and alcohol use and their possible consequences were raised in a nonconfrontational manner using FRAMES (Bien et al., 1993) and reflective listening techniques. All BIG participants received the same alcohol intervention via printed materials derived from the TrEAT (Fleming et al., 1997) manuals but also adapted to include risky driving information. The interviewer recommended safe driving practices with a focus on reducing the most prevalent risk-taking driving behaviors (i.e., lack of safety belt restraint, speeding, failure to yield, failure to stop, running red and yellow lights, driver inattention, drink-driving). The intervention contained a list of safe driving practices and promoted behaviors such as wearing a seat belt in all positions in the car, following the posted speed limit, avoiding an intersection when the light is yellow or red, using the left lane for passing, avoiding tailgating, distancing themselves from other drivers, and avoiding driving when overtired or under the influence of alcohol and/or drugs. 
Information on alcohol use included a drinking typology (dependent, heavy, and low-risk drinkers), the early consequences of heavy drinking, and tips to cut down on drinking. All participants in the intervention group received feedback about their current risky driving and hazardous drinking behaviors. The interviewer then guided participants through a discussion of the pros and cons of changing driving behaviors and hazardous drinking, offered an opportunity to examine situations where participants were tempted to use risky behaviors, and initiated a contract for both behaviors that participants were willing to change. All intervention participants received SBIRT for both risky driving and problem drinking.

In the booster intervention 10 to 14 days after discharge, participants discussed whether they were able to meet the contract goals. The outcomes of the initial agreement were used as a framework to explore situations in which the participant had been most tempted to drive in an unsafe manner or drink beyond the recommended limits. The participant and interviewer then renegotiated the contract.

The assessment, brief intervention, and booster intervention were delivered by 4 nurse clinicians employed by the study team. While the nurses were not employed by the ED that was the site of the study, they received an 8-hour orientation to the study site by the coprincipal investigator, an ED faculty member. The nurse clinicians received 24 hours of training in SBIRT by a social psychologist expert (Bien et al., 1993). Following the end of training and once every 6 months during participant enrollment, the nurse clinicians were videotaped interviewing proxy participants and delivering the intervention to them. During the course of study enrollment, each nurse clinician was videotaped and evaluated at least 5 times. These interviews were rated by outside experts, who recommended retraining if needed. No retraining was needed during the course of the study. No actual clinicianparticipant interactions were recorded for fidelity checks during the course of the study.

\section{Data Collection Procedures}

For the BIG and CCG, trained research assistants conducted telephone interviews at 3, 6, 9, and 12 months. The same interview guide was used at baseline and for all data collection points. The NCG participants were contacted at 3,6, and 9 months only to update contact information and were interviewed at 12 months. Interviewers were blinded to condition during the follow-up interviews. Participants in all 3 groups received $\$ 20$ for each of the baseline, 3-, 6-, and 9-month interviews and $\$ 40$ for the 12-month interview.

\section{Outcome Measures}

Primary outcome measures included self-reported risky driving behaviors (presence of safety belt use and times speeding in the previous 30-day period) and alcohol consumption (drinking $\geq 5$ standard drinks/d on drinking days and maximum number of standard drinks within in a 6-hour period).

The seat belt questions were taken from Eby and colleagues (Eby and Vivoda, 2003; Eby et al., 2000). The speeding questions were taken from the speeding domain of the DDBI, which has 7 risky driving domains (speeding, a 3-item scale [Cronbach's alpha $=0.77$; passing violations, a 3 -item scale [alpha $=0.66$ ]; following violations, a 2 -item scale [alpha $=0.76]$; lane-usage violations, a 4 -item scale [alpha $=0.76$ ]; right-of-way violations, a 2- 
item scale [alpha $=0.62$ ]; turn violations, a 3-item scale [alpha $=0.72$ ]; and control signal violations, a 3-item scale [alpha $=0.70]$; Donovan, 1993). Alcohol consumption was measured with 2 quantity/frequency questions: (i) In a typical week, how many times do you have 5 or more drinks ( 4 or more for women) at 1 sitting (during a 6-hour time period)? and (ii) What is the maximum number of drinks you have had on any given occasion (during a 6hour time period) in the last 3 months? Secondary hazardous drinking outcomes were measured with the 10 questions from the AUDIT (Allen et al., 1997; Cherpitel, 1995; Reinert and Allen, 2007; Saunders et al., 1993). In their extensive review of the psychometric properties of the AUDIT, Reinert and Allen (2007) found that the AUDIT's sensitivities and specificities compared favorably to and generally exceeded those of other alcohol screening methods; sensitivities and specificities the AUDIT generally ranged above 0.85 in most populations. They also found that in a broad range of diverse samples and settings, the AUDIT has a high degree of internal consistency (Reinert and Allen, 2007).

Secondary outcome measures included additional measures of risky driving and hazardous drinking. Risky driving was measured by the 7 DDBI domains (Donovan, 1993). Binge drinking was defined as 5 or more drinks during a 6-hour occasion for men and 4 or more for women. Adverse driving events were defined as traffic violations reported on motor vehicle records issued by the state of licensure as well as traffic crash reports from local police jurisdictions. Due to the small number of individuals who had more than one of each driving abstract event, the data were recoded as either no events (0) or one or more (1). To assess cognitive functioning, participants in the BIG and CCG were administered the Stroop psychological test of executive functioning in the baseline interview (Spreen and Strauss, 2006; Trenerry et al., 1989).

\section{Statistical Analysis}

A sample of 133 participants were required per group to attain power of $80 \%$ to detect an effect of at least 35\% between the BIG and CCG, assuming 70\% retention (comparable to retention in previous studies; Longabaugh et al., 2001; Sommers et al., 2006). Although participants were randomized to condition at baseline, the distributions of participant demographic and enrollment-related characteristics were compared across treatment conditions at baseline as well as across time using analyses that best matched the nature of the data, including generalized linear models, $t$ - and chi-square tests. Generalized linear mixed models were used to evaluate the brief intervention's effect on longitudinal drinking and driving outcomes measured at 3-month intervals. Logistic models were used for binary outcomes and Poisson (or quasi-Poisson to account for overdispersion) models for count outcomes. Effects are thus presented in terms of adjusted odds ratios (AORs) from logistic models and adjusted rate ratios (ARRs) from Poisson models. Age, sex, race (White, nonWhite), education ( $<$ high school, high school, > high school), income, insurance status (presence/absence), treatment condition (BIG, NCG, CCG), seasonality (Summer, Fall, Winter, Spring), Stroop scores, years of driving experience, and driving exposure (miles/y) were initially included as covariates, and random effects were included for time. Final models, however, only adjusted for the significant effects of age, sex, education, and race. To evaluate the intervention's effect over time, interactions between time, time-squared (to account for nonlinear change), and treatment condition (BIG, CCG) were included. 
To determine whether the intervention's effect varied as a function of age and sex, secondary analyses included 3-way interactions between age or sex and both treatment condition and time. Due to skewness and outliers in the data, medians and the interquartile ranges are presented in our tables of descriptive statistics instead of means and standard deviations. All statistical analyses were performed according to intention to treat. Missing data were imputed using hot-decking techniques (Andridge and Little, 2010). Analyses were conducted using the R environment for statistical computing (R TEAM, 2010).

\section{RESULTS}

Of the 20,027 participants who were screened, 834 were eligible for study enrollment (see Fig. 1). Of those screened, 745 refused or were not screened, 9,735 were excluded due to (i) age ( $<18$ or $>45$ ), (ii) being in police custody, or (iii) not registered as an ED patient. An additional 1,449 did not complete screening. Of the remaining individuals who were eligible and completed screening ( $n=8,098), 2,116$ screened positive for risky driving only (26.1\%), 926 screened positive for hazardous drinking only (11.4\%), 834 screened positive to both risky driving and hazardous drinking (10.3\%), and 4,222 (52.1\%) screened negatively to both risky driving and hazardous drinking.

Retention over 12 months was 69\% (BIG 65\%, CCG 67\%, and NCG 74\%). A majority of the sample was non-White (63\%), male (70\%), and did not have insurance (56\%; see Table 1). No significant differences in demographic characteristics were observed among groups at baseline, among retained participants at 12-month follow-up, or between retained participants and those lost to follow-up $(p>0.05)$. However, a significant baseline difference $(p<0.05)$ between the BIG $(31 \%)$ and CCG $(43 \%)$ was observed in terms of the proportion of participants with an AUDIT score $\geq 10$. Figure 2 illustrates the effect of the intervention for each primary or secondary risky driving and hazardous drinking outcome that significantly differed between the BIG and CCG over time.

\section{Risky Driving}

Table 2 presents unadjusted descriptive statistics for each risky driving outcome by time period and group. As compared with controls, participants in the BIG demonstrated significant declines in the primary driving outcome of nonsafety belt use at 3 months (AOR, 0.22 ; $95 \%$ confidence interval [CI], 0.08 to 0.65 ), 6 months (AOR, $0.13 ; 95 \% \mathrm{CI}, 0.04$ to 0.42 ), and 9 months (AOR, $0.18 ; 95 \% \mathrm{CI}, 0.06$ to 0.56 ), with the BIG decreasing their frequency of not always wearing a safety belt by $6 \%$, while the CCG actually increased nonsafety belt practices by $10 \%$. The intervention did not show an effect for the other primary driving variable, number of times speeding $\geq 20 \mathrm{mph}$ over the speed limit (a low frequency behavior). However, there was a positive effect for number of times speeding 10 to 19 mph over the speed limit at 3 months (ARR, 0.37; 95\% CI, 0.17 to 0.80 ), 6 months (ARR, $0.22 ; 95 \% \mathrm{CI}, 0.10$ to 0.50 ), and 9 months (ARR, 0.36 ; $95 \% \mathrm{CI}, 0.13$ to 0.95 ). Several secondary risky driving outcomes demonstrated significant declines in the BIG as compared with the CCG. Running yellow lights was less frequent among the BIG as compared with the CCG at 3,6, and 9 months and not stopping fully at stop signs differed only at the 3- and 6-month follow-up (see Table 2 and Fig. 2). 
The intervention's effectiveness did not vary as a function of age or sex for any risky driving outcome. After adjusting for demographic characteristics and baseline measurements, the effect of the intervention was nonsignificant for driving abstract and self-reported traffic crashes at 12-month follow-up (see Table 3). However, several of these outcomes declined significantly within each group over time.

\section{Hazardous Drinking}

Table 4 presents unadjusted descriptive statistics for each hazardous drinking outcome by time period and group. Both primary hazardous drinking measures declined significantly in the BIG compared with the CCG: maximum number of drinks within a 6-hour period at 3 months (ARR, 0.84; 95\% CI, 0.74 to 0.97) and 6 months (ARR, 0.81; 95\% CI, 0.67 to 0.97), with the BIG showing a 2 drink decrease per drinking session from baseline compared with only a 1 drink decrease for the CCG; and drinking $\geq 5$ drinks/d at 3 months (AOR, 0.43; 95\% CI, 0.20 to 0.91 ) and 6 months (AOR, $0.41 ; 95 \%$ CI, 0.17 to 0.98 ), with the BIG showing a $20 \%$ decrease in this behavior from baseline compared with only a $10 \%$ decrease for the CCG. The effect on these outcomes did not persist beyond the 6-month follow-up. A significant 3-way interaction between sex, group, and time indicated that the intervention resulted in greater positive effects for men than women over time, in terms of curtailing hazardous drinking behavior. There were no significant effects for any of our secondary drinking outcomes.

As the proportion of participants who had AUDIT scores $>10$ significantly differed between BIG and CCG conditions at baseline, we conducted an additional statistical analysis wherein the baseline AUDIT measurement was included as a covariate and change in this outcome for the remaining time points was modeled; similar results were found from this analysis in that there was no significant change over time in the proportion of participants with AUDIT $>10$ as a function group assignment.

\section{Drinking-Driving Secondary Outcomes}

We obtained self-reported counts of the number of times individuals engaged in the following drinking and driving behaviors in the previous 3-month period: (i) driving within an hour after drinking 1 or 2 beers or other alcoholic beverages; (ii) driving within an hour after drinking 3 or more beers or other alcoholic beverages; (iii) driving when feeling high or light-headed from drinking; (iv) driving when knowing drinking may have affected coordination; and (v) drinking in the car while driving. In each case, the frequency of occurrence of such behaviors was low (medians for all variables at all time points were near 0 and interquartile ranges mostly between 0 and 4 events), and the results of statistical modeling were similar in that significant differences were observed between the BIG (lower rates) and CCG at the 3- and 6-month follow-up only. As an illustrative example, we present results for one of these outcomes in Table 2, driving within an hour of drinking 3 or more beers or alcoholic beverages.

\section{Comparison of CCG and NCG at 12-Month Follow-Up}

Results showed no significant differences between the NCG (no assessment and no intervention) and CCG (assessment and no intervention) at 12-month follow-up for 
hazardous drinking outcomes (Bonferroni-adjusted, $p>0.003$ ). However, the frequency for 2 risky driving outcomes was significantly higher in the NCG as compared with the CCG at the 12-month follow-up: frequency of driving 10 to $19 \mathrm{mph}$ over the speed limit (ARR, 0.27; 95\% CI, 0.10 to 0.71 ) and driving through a yellow light as it changed to red (ARR, 0.42; $95 \%$ CI, 0.28 to 0.63 ); although the frequency of both risky driving variables only differed by a single occurrence between groups (median $=4$ and 5 for the CCG and NCG, respectively, for both driving outcomes), suggesting little clinical difference at 12-month follow-up.

\section{DISCUSSION}

Our results demonstrated that SBIRT addressing risky driving and hazardous drinking has a significant effect on risky driving for 9 months and on hazardous drinking for 6 months in a population of nonalcohol-dependent ED patients who screen positive for both healthcompromising behaviors. Given the extent of public health problems associated with vehicle-related injuries and alcohol use, a clinically feasible intervention that reduces risky driving and hazardous drinking offers the potential to reduce the disease burden of both. The recent decision by the Joint Commission to include screening and brief interventions related to alcohol use as one of its national hospital inpatient quality measures reflects the growing evidence that such interventions have a valuable role to play at the intersection of public health and clinical care (The Joint Commission, 2012). Our findings add further support for this direction, and add evidence about the potential for SBIRT to improve outcomes in a new area, namely risky driving.

In terms of the clinical utility, the number needed to treat (NNT) to reduce or prevent the occurrence of these risk behaviors in a single individual would be 6 participants for increased safety belt use. The NNT to reduce drinking below the hazardous level ( 5 or more alcoholic drinks/d) would be 7 participants. The clinical importance of reductions in risky driving and hazardous drinking is profound. The risky driving behaviors that were significantly decreased at 9 months in the intervention group included such lifesaving behaviors such as increased safety belt use, increased adherence to traffic signals, reduced speeding, and reduced driving after drinking. The National Highway Traffic Safety Administration reports that safety belts save over 11,000 traffic deaths a year and conversely, running red lights causes up to 900 fatal crashes a year (Retting et al., 2008). Speeding is clearly associated with increased mortality from crashes (Gonzalez et al., 2007). Changing these behaviors has the potential for significant health benefits.

The proportion of participants consuming $\geq 5$ drinks/d and binge drinking was significantly lower among the BIG compared with the CCG at 3 and 6 months. These findings replicated those of Walton and colleagues (2010) who followed adolescents for 6 months, but they differ from the findings of other trials. While several investigators found significant decreases in hazardous drinking at 12 months after intervention (Blow et al., 2006; D’Onofrio et al., 2012; Longabaugh et al., 2001; Monti et al., 2007) others found no differences between intervention and control groups (Academic ED SBIRT Research Collaborative, 2010; Cherpitel et al., 2010; Daeppen et al., 2007; Maio et al., 2005). The role of ED-delivered interventions for hazardous drinking remains a fertile area for ongoing 
research. While no definitive answer exists about the effectiveness of SBIRT to reduce hazardous drinking in the ED population, refinement of the best dose and appropriate target remains clinically important.

By including an NCG and an assessment only group (CCG), our study also offers insights into whether screening and assessment themselves are a form of intervention (Bernstein and Bernstein, 2008). Protocols in SBIRT trials may include as much as a 20-minute assessment battery that may lead to "assessment reactivity" (Daeppen et al., 2007; D'Onofrio et al., 2008, 2012). In our sample, the frequencies for 2 risky driving outcomes, but not the primary drinking outcomes, were significantly, but only slightly, higher in the NCG as compared with the CCG at the 12-month follow-up. Additionally, the 20 minutes of screening received by the CCG was not a substitute for the screening plus SBIRT received by the BIG. These findings suggest that screening alone is not likely a strong enough intervention to change health-compromising behaviors such as risky driving and hazardous drinking in the ED population.

\section{LIMITATIONS}

We experienced a $22 \%$ refusal rate in study participation. In addition to possible concerns about potential legal jeopardy from risky driving behaviors, some patients were in pain or tired due to their medical condition, which may have limited their willingness to participate. An additional 162 (19\% of the eligible sample) patients who screened positive for risky driving and hazardous drinking were not enrolled. Common reasons were that patients left the ED before seeing research assistants, or the patients were unexpectedly admitted to the hospital and therefore not eligible. The study's findings might have differed had these patients enrolled, but it is difficult to speculate on the direction of any bias.

Although the 69\% retention rate exceeded the 3-month (Bazargan-Hejazi et al., 2005) and 12-month retention rates (Cherpitel et al., 2010) of other SBIRT trials in the ED, the level of attrition may have biased the study findings in either direction. However, our sensitivity analyses suggested no substantial demographic or study-related differences in retained and nonretained samples. Because we screened outpatients with AUDIT scores of $\geq 2$ on any or all of the 3 alcohol dependence items, our findings do not apply to those who may be alcohol dependent.

Measures of risky driving behaviors and alcohol consumption were based on self-reported data, although the risky driving behaviors were also measured with state licensing and police records. Recall or social desirability bias may be relevant concerns that might increase the apparent efficacy of the intervention. The study focused on a single ED in 1 Midwestern city, which limits generalizability of the findings. Finally, we did not explore the role of text messaging and other technologies that emerged after the study began (Drews et al., 2009; Hosking et al., 2009; Wilson and Stimpson, 2010).

\section{CONCLUSION}

Our results support the efficacy of an ED intervention for risky driving up to 9 months and for hazardous drinking up to 6 months in a population of nonalcohol-dependent young adults 
who screen positive for both health-compromising behaviors. To date, risky driving, a leading cause of significant threats to health and safety, has received little attention in behavioral intervention trials (Shope and Bingham, 2008; Sommers et al., 2011; Williams et al., 2007). Our study indicates that risky driving is a modifiable risk factor for injury and should be considered alongside hazardous drinking as a potential target for SBIRT.

\section{Acknowledgments}

This work was funded by a grant (R49/CCR-523225) from the National Center for Injury Prevention and Control, Centers for Disease Control and Prevention (PI: MSS).

\section{REFERENCES}

Academic ED SBIRT Research Collaborative. The impact of screening, brief intervention and referral for treatment in emergency department patients' alcohol use: a 3-, 6- and 12-month follow-up. Alcohol Alcohol. 2010; 45:514-519. [PubMed: 20876217]

Allen JP, Litten RZ, Fertig JB, Babor T. A review of research on the Alcohol Use Disorders Identification Test (AUDIT). Alcohol Clin Exp Res. 1997; 21:613-619. [PubMed: 9194913]

Andridge RR, Little RJA. A review of hot deck imputation for survey non-response. Int Stat Rev. 2010; 78:40-64. [PubMed: 21743766]

Bazargan-Hejazi S, Bing E, Bazargan M, Der-Martirosian C, Hardin E, Bernstein J, Bernstein E. Evaluation of a brief intervention in an inner-city emergency department. Ann Emerg Med. 2005; 46:67-76. [PubMed: 15988430]

Bernstein E, Bernstein J. Effectiveness of alcohol screening and brief motivational intervention in the emergency department setting. Ann Emerg Med. 2008; 51:751-754. [PubMed: 18436342]

Bien TH, Miller WR, Tonigan JS. Brief intervention for alcohol problems: a review. Addiction. 1993; 88:315-336. [PubMed: 8461850]

Bingham CR, Shope JT, Tang X. Drinking behavior from high school to young adulthood: differences by college education. Alcohol Clin Exp Res. 2005; 29:2170-2180. [PubMed: 16385187]

Blow FC, Barry KL, Walton MA, Maio RF, Chermack ST, Bingham CR, Ignacio RV, Strecher VJ. The efficacy of two brief intervention strategies among injured, at-risk drinkers in the emergency department: impact of tailored messaging and brief advice. J Stud Alcohol. 2006; 67:568-578. [PubMed: 16736077]

Blow FC, Walton MA, Barry KL, Murray RL, Cunningham RM, Massey LS, Chermack ST, Booth BM. Alcohol and drug use among patients presenting to an inner-city emergency department: a latent class analysis. Addict Behav. 2011; 36:793-800. [PubMed: 21514734]

CDC. National Hospital Ambulatory Medical Care Survey: 2008 Emergency Department Summary. Center for Disease Control and Prevention; Hyattsville, MD: 2012.

Cherpitel CJ. Analysis of cut points for screening instruments for alcohol problems in the emergency room. J Stud Alcohol Drugs. 1995; 56:695-700.

Cherpitel CJ, Korcha RA, Moskalewicz J, Swiatkiewicz G, Ye Y, Bond J. Screening, brief intervention, and referral to treatment (SBIRT): 12-month outcomes of a randomized controlled clinical trial in a Polish emergency department. Alcohol Clin Exp Res. 2010; 34:1922-1928. [PubMed: 20659072]

Daeppen JB, Gaume J, Bady P, Yersin B, Calmes JM, Givel JC, Gmel G. Brief alcohol intervention and alcohol assessment do not influence alcohol use in injured patients treated in the emergency department: a randomized controlled clinical trial. Addiction. 2007; 102:1224-1233. [PubMed: 17565563]

D’Onofrio G, Fiellin DA, Pantalon MV, Chawarski MC, Owens PH, Degutis LC, Busch SH, Bernstein SL, O'Connor PG. A brief intervention reduces hazardous and harmful drinking in emergency department patients. Ann Emerg Med. 2012; 60:181-192. [PubMed: 22459448] 
D’Onofrio G, Pantalon MV, Degutis LC, Fiellin DA, Busch SH, Chawarski MC, Owens PH, O'Connor PG. Brief intervention for hazardous and harmful drinkers in the emergency department. Ann Emerg Med. 2008; 51:742-750. [PubMed: 18436340]

Donovan JE. Young adult drinking-driving: behavioral and psychosocial correlates. J Stud Alcohol Drugs. 1993; 54:600-613.

Drews FA, Yazdani H, Godfrey CN, Cooper JM, Strayer DL. Text messaging during simulated driving. Hum Factors. 2009; 51:762-770. [PubMed: 20196300]

Eby DW, Molnar LJ, Olk M. Trends in driver and front-right passenger safety belt use in Michigan: 1984-1998. Accid Anal Prev. 2000; 32:837-843. [PubMed: 10994611]

Eby DW, Vivoda JM. Driver hand-held mobile phone use and safety belt use. Accid Anal Prev. 2003; 35:893-895. [PubMed: 12971923]

Fernandez WG, Winter MR, Mitchell PM, Bullock H, Donovan J, St George J, Feldman JA, Gallagher SS, McKay MP, Bernstein E, Colton T. Six-month follow-up of a brief intervention on selfreported safety belt use among emergency department patients. Acad Emerg Med. 2009; 16:12211224. [PubMed: 19814758]

Fields WW, Asplin BR, Larkin GL, Marco CA, Johnson LA, Yeh C, Ghezzi KT, Rapp M. The Emergency Medical Treatment and Labor Act as a federal health care safety net program. Acad Emerg Med. 2001; 8:1064-1069. [PubMed: 11691669]

Fleming MF, Barry KL, Manwell LB, Johnson K, London R. Brief physician advice for problem alcohol drinkers. A randomized controlled trial in community-based primary care practices. JAMA. 1997; 277:1039-1045. [PubMed: 9091691]

Gonzalez RP, Cummings GR, Phelan HA, Harlin S, Mulekar M, Rodning CB. Increased rural vehicular mortality rates: roadways with higher speed limits or excessive vehicular speed? J Trauma. 2007; 63:1360-1363. [PubMed: 18212661]

Hosking SG, Young KL, Regan MA. The effects of text messaging on young drivers. Hum Factors. 2009; 51:582-592. [PubMed: 19899366]

Houry D, Hankin A, Daugherty J, Smith LS, Kaslow N. Effect of a targeted women's health intervention in an inner-city emergency department. Emerg Med Int. 2011; 2011:543493. [PubMed: 22203904]

Jiang N, Kolbe LJ, Seo DC, Kay NS, Brindis CD. Health of adolescents and young adults: trends in achieving the 21 critical national health objectives by 2010. J Adolesc Health. 2011; 49:124-132. [PubMed: 21783043]

Llovera I, Ward MF, Ryan JG, LaTouche T, Sama A. A survey of the emergency department population and their interest in preventive health education. Acad Emerg Med. 2003; 10:155-160. [PubMed: 12574014]

Longabaugh R, Woolard RE, Nirenberg TD, Minugh AP, Becker B, Clifford PR, Carty K, Licsw Sparadeo F, Gogineni A. Evaluating the effects of a brief motivational intervention for injured drinkers in the emergency department. J Stud Alcohol. 2001; 62:806-816. [PubMed: 11838918]

MacCambridge J. Research assessments: instruments of bias and brief interventions of the future? Addiction. 2009; 104:1311-1312. [PubMed: 19624324]

Maio RF, Shope JT, Blow FC, Gregor MA, Zakrajsek JS, Weber JE, Nypaver MM. A randomized controlled trial of an emergency department-based interactive computer program to prevent alcohol misuse among injured adolescents. Ann Emerg Med. 2005; 45:420-429. [PubMed: 15795723]

Mello MJ, Longabaugh R, Baird J, Nirenberg T, Wollard R. DIAL: a telephone brief intervention for high-risk alcohol use with injured emergency department patients. Ann Emerg Med. 2008; 51:755-764. [PubMed: 18436341]

Monti PM, Barnett NP, Colby SM, Gwaltney CJ, Spirito A, Rohsenow DJ, Woolard R. Motivational interviewing versus feedback only in emergency care for young adult problem drinking. Addiction. 2007; 102:1234-1243. [PubMed: 17565560]

National Institute on Alcohol Abuse and Alcoholism (NIAAA). [Accessed April 7, 2013] What is lowrisk drinking [Online]. 2011. Available at: http://rethinkingdrinking.niaaa.nih.gov/ Is YourDrinkingPatternRisky/WhatsLowRiskDrinking.asp 
Naumann RB, Dellinger AM, Zaloshnja E, Lawrence BA, Miller TR. Incidence and total lifetime costs of motor vehicle-related fatal and nonfatal injury by road user type, United States, 2005. Traffic Inj Prev. 2010; 11:353-360. [PubMed: 20730682]

Park MJ, Paul Mulye T, Adams SH, Brindis CD, Irwin CE. The health status of young adults in the United States. J Adolesc Health. 2006; 39:305-317. [PubMed: 16919791]

Patil S, Shope JT, Raghunathan TE, Bingham CR. The role of personality characteristics in young adult driving. Traffic Inj Prev. 2006; 7:328-334. [PubMed: 17114089]

R TEAM. R: A Language and Environment for Statistical Computing. R. R TEAM; Vienna, Austria: 2010.

Reinert DF, Allen JP. The Alcohol Use Disorders Identification Test: an update of research findings. Alcohol Clin Exp Res. 2007; 31:185-199. [PubMed: 17250609]

Retting RA, Ferguson SA, Farmer CM. Reducing red light running through longer yellow signal timing and red light camera enforcement: results of a field investigation. Accid Anal Prev. 2008; 40:327-333. [PubMed: 18215565]

Rhodes KV, Gordon JA, Lowe RA. Preventive care in the emergency department, part I: clinical preventive services - are they relevant to emergency medicine? Society for Academic Emergency Medicine Public Health and Education Task Force Preventive Services Work Group. Acad Emerg Med. 2000; 7:1036-1041. [PubMed: 11044001]

Saunders JB, Aasland OG, Babor TF, de la Fuente JR, Grant M. Development of the Alcohol Use Disorders Identification Test (AUDIT): WHO collaborative project on early detection of persons with harmful alcohol consumption-II. Addiction. 1993; 88:791-804. [PubMed: 8329970]

Shope JT, Bingham CR. Drinking-driving as a component of problem driving and problem behavior in young adults. J Stud Alcohol Drugs. 2002; 63:24-33.

Shope JT, Bingham CR. Teen driving: motor-vehicle crashes and factors that contribute. Am J Prev Med. 2008; 35:S261-S271. [PubMed: 18702980]

Sloan F, Grossman D, Platt A. Heavy episodic drinking in early adulthood and outcomes in midlife. J Stud Alcohol Drugs. 2011; 72:459-470. [PubMed: 21513683]

Sommers BD, Fargo JD, Lyons MS, Shope JT, Sommers MS. Societal costs of risky driving: an economic analysis of high-risk patients visiting an urban emergency department. Traffic Inj Prev. 2011; 12:149-158. [PubMed: 21469022]

Sommers MS, Dyehouse JM, Howe SR, Fleming M, Fargo JD, Schafer JC. Effectiveness of brief interventions after alcohol-related vehicular injury: a randomized controlled trial. J Trauma. 2006; 61:523-531. discussion 532-533. [PubMed: 16966982]

Spreen, O.; Strauss, E. A Compendium of Neuropsychological Tests: Administration, Norms, and Commentary. Oxford University Press; Oxford: 2006.

Stewart SH, Borg KT, Miller PM. Prevalence of problem drinking and characteristics of a singlequestion screen. J Emerg Med. 2010; 39:291-295. [PubMed: 18534807]

Tang N, Stein J, Hsia RY, Maselli JH, Gonzales R. Trends and characteristics of US emergency department visits, 1997-2007. JAMA. 2010; 304:664-670. [PubMed: 20699458]

The Joint Commission. [Accessed April 7, 2013] Substance use: the SUB measure set. 2012. Available at: http://www.jointcommission.org/substance_use/

Trenerry, M.; Crosson, B.; Deboe, J.; Leber, W. Stroop Neuropsychological Screening Test. Psychological Assessment Resources; Odessa, FL: 1989.

Walton MA, Chermack ST, Shope JT, Bingham CR, Zimmerman MA, Blow FC, Cunningham RM. Effects of a brief intervention for reducing violence and alcohol misuse among adolescents: a randomized controlled trial. JAMA. 2010; 304:527-535. [PubMed: 20682932]

Walton MA, Goldstein AL, Chermack ST, McCammon RJ, Cunningham RM, Barry KL, Blow FC. Brief alcohol intervention in the emergency department: moderators of effectiveness. J Stud Alcohol Drugs. 2008; 69:550-560. [PubMed: 18612571]

Williams, S.; Whitlock, E.; Smith, P.; Edgerton, B.; Beil, T. U.S. Preventive Services Task Force Evidence Syntheses. Agency for Healthcare Research and Quality (US); Rockville (MD): Aug.. 2007 Primary Care Interventions to Prevent Motor Vehicle Occupant Injuries. 2007Report No.: 07-05103-EF-1 
Wilson FA, Stimpson JP. Trends in fatalities from distracted driving in the United States, 1999 to 2008. Am J Public Health. 2010; 100:2213-2219. [PubMed: 20864709]

World Health Organization (WHO). Global Status Report on Road Safety: Time for Action. World Health Organization; Geneva: 2009. Available at: http://www.who.int/violence_injury_prevention/ road_safety_status/2009 [Accessed April 7, 2013] 


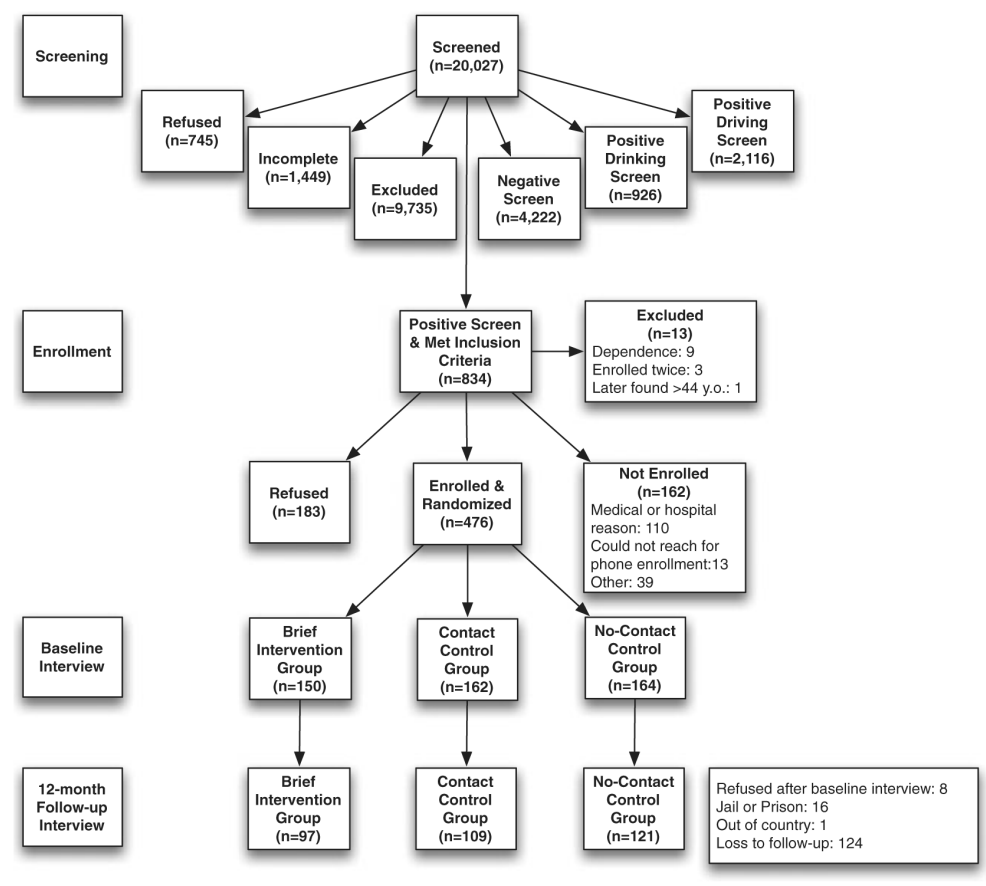

Fig. 1.

Flowchart depicting sample for Screening, Brief Intervention, and Referral to Treatment (SBIRT) study, including stages for screening, enrollment, random assignment, retention, and analysis. 


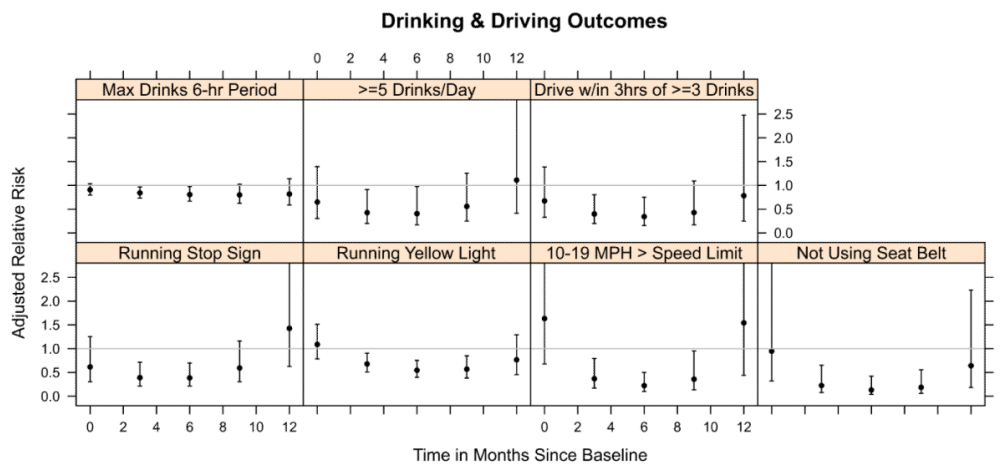

Fig. 2.

Odds and rate ratios (adjusted for age, sex, education, and race) and their $95 \%$ confidence intervals (CIs) indicating the impact of the intervention for drinking and driving outcomes over time. Ratios and their CIs $<1.0$ indicate significant treatment effects (i.e., effect in the brief intervention group was greater than in the contact control group). All participants were included in these analyses. 
Table 1

Demographic Characteristics of Study Sample at Baseline, Stratified by Group Assignment

\begin{tabular}{lcccc}
\hline & BIG & CCG & NCG & $p$ \\
\hline Age, years & $28(23-34)$ & $26(23-34)$ & $28.5(23-34.5)$ & 0.7265 \\
Female & $54(36.0 \%)$ & $45(27.8 \%)$ & $44(26.8 \%)$ & 0.1218 \\
Non-White & $89(59.3 \%)$ & $103(63.6 \%)$ & $105(64.0 \%)$ & 0.3956 \\
Education < high school & $25(16.7 \%)$ & $29(17.9 \%)$ & $29(17.7 \%)$ & 0.8231 \\
Education = high school & $57(38.0 \%)$ & $55(34.0 \%)$ & $67(40.9 \%)$ & \\
Education > high school & $68(45.3 \%)$ & $78(48.1 \%)$ & $68(41.5 \%)$ & \\
Married or has significant other & $89(59.3 \%)$ & $89(55.3 \%)$ & $106(64.6 \%)$ & 0.1169 \\
Insured & $57(38.3 \%)$ & $73(45.9 \%)$ & $71(44.1 \%)$ & 0.2157 \\
Employed full time & $74(49.7 \%)$ & $97(60.6 \%)$ & $99(60.4 \%)$ & 0.1073 \\
Employed part time & $33(22.1 \%)$ & $27(16.9 \%)$ & $19(11.6 \%)$ & \\
Not employed & $42(28.2 \%)$ & $36(22.5 \%)$ & $46(28.0 \%)$ & \\
$<6$ years driving experience & $26(17.6 \%)$ & $40(24.8 \%)$ & - & 0.4820 \\
Drove > 15K+ miles last year & $60(43.5 \%)$ & $65(42.8 \%)$ & - & 0.9742 \\
Drove 11-15K miles last year & $23(16.7 \%)$ & $30(19.7 \%)$ & - & \\
Drove < 11K miles last year & $55(39.9 \%)$ & $57(37.5 \%)$ & - & \\
Stroop Test-Color-Word (raw score) & $105(87-117)$ & $101(87-118.5)$ & $96(79-117)$ & 0.2235 \\
Days little to no exercise & $8(0-24.5)$ & $7(0-20)$ & $8(0-20)$ & 0.7067 \\
Days ate fast food & $9.5(3.5-20)$ & $10(5-21)$ & $10(5-20)$ & 0.3295 \\
Cigarettes smoked daily & $5(0-14.5)$ & $5(0-20)$ & $4(0-20)$ & 0.6666 \\
Nights < 7 hours sleep & $15(5-30)$ & $15(4-30)$ & $15(5-30)$ & 0.9266 \\
$\geq 1$ Traffic crash from police records & $15(10.3 \%)$ & $18(11.8 \%)$ & $15(9.7 \%)$ & 0.8371 \\
$\geq 1$ Traffic offense from police records & $22(15.1 \%)$ & $24(15.7 \%)$ & $31(20.1 \%)$ & 0.4399 \\
$\geq 1$ Traffic citation from police records & $59(40.4 \%)$ & $59(38.6 \%)$ & $55(35.7 \%)$ & 0.6998 \\
$\geq 1$ Alcohol-related traffic offense from police records & $5(3.4 \%)$ & $6(3.9 \%)$ & $6(3.9 \%)$ & 0.9683 \\
\hline & & & -19 \\
\end{tabular}

Values represent $N(\%)$ or median (interquartile range). Screening questions pertain to the previous month. $p$-Values are from $t$-tests (continuous variable) or chi-square tests (categorical variables). BIG, brief intervention group; CCG, contact control group; NCG, no-contact control group. 


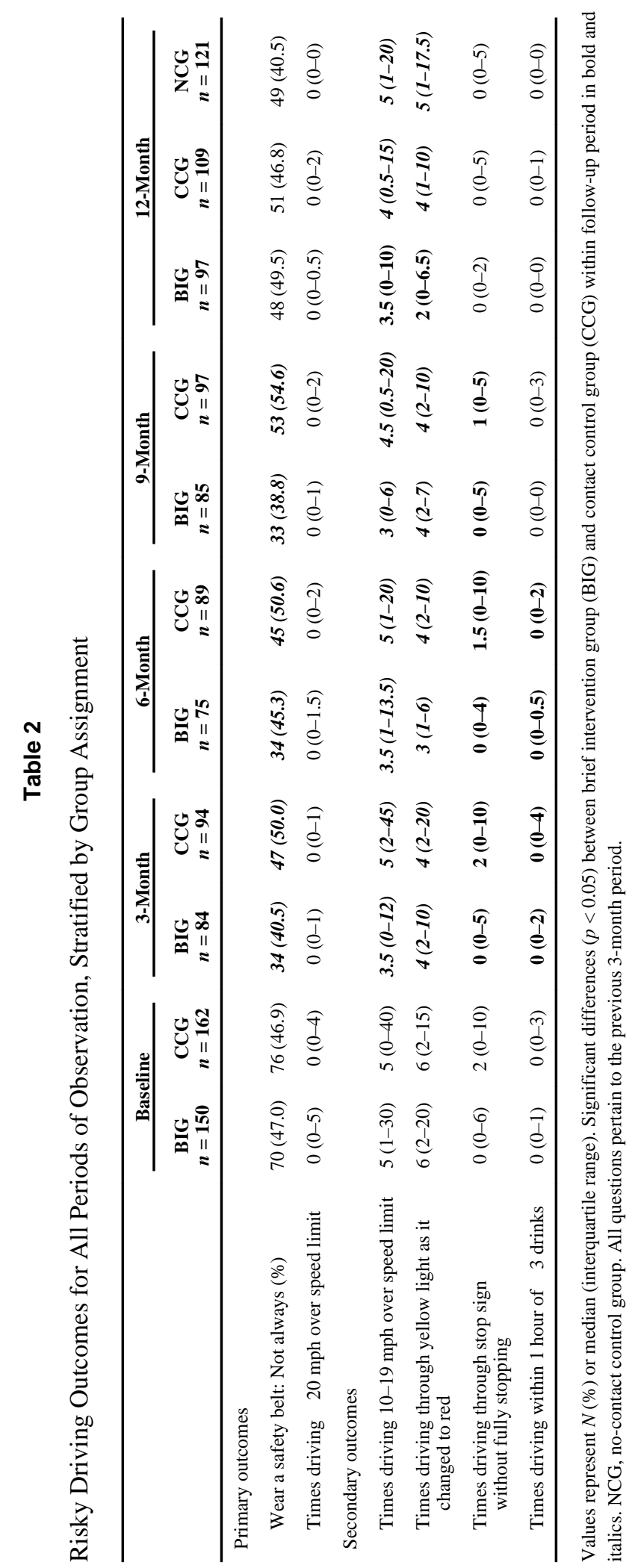


Table 3

Driving Abstract and Self-Reported Crash Outcomes, Stratified by Group Assignment

\begin{tabular}{|c|c|c|c|c|c|c|}
\hline & \multicolumn{3}{|c|}{ Baseline } & \multicolumn{3}{|c|}{ 12-Month } \\
\hline & $\begin{array}{c}\text { BIG }(\%) \\
n=150\end{array}$ & $\begin{array}{c}\text { CCG }(\%) \\
n=162\end{array}$ & $\begin{array}{c}\text { NCG }(\%) \\
n=164\end{array}$ & $\begin{array}{c}\text { BIG }(\%) \\
n=97\end{array}$ & $\begin{array}{c}\text { CCG }(\%) \\
n=109\end{array}$ & $\begin{array}{c}\text { NCG }(\%) \\
n=121\end{array}$ \\
\hline Self-reported traffic crashes: 1 or more events & $22(14.7)$ & $29(17.9)$ & - & $10(10.3)$ & $7(6.4)$ & $13(10.7)$ \\
\hline Traffic crashes: 1 or more events & $15(10.0)$ & $18(11.1)$ & $15(9.2)$ & $27(27.8)$ & $29(26.6)$ & $35(28.9)$ \\
\hline Self-reported traffic tickets: 1 or more events & $57(38.0)$ & $63(38.9)$ & - & $10(10.3)$ & $18(16.5)$ & $10(8.3)$ \\
\hline Traffic offenses: 1 or more events & $22(14.7)$ & $24(14.8)$ & $31(18.9)$ & $32(33.0)$ & $32(29.4)$ & $37(30.6)$ \\
\hline Traffic citations: 1 or more events & $59(39.3)$ & $59(36.4)$ & $55(33.5)$ & $4(4.1)$ & $6(5.5)$ & $3(2.5)$ \\
\hline Alcohol-related traffic offenses: 1 or more events & $5(3.3)$ & $6(3.7)$ & $6(3.7)$ & $10(10.3)$ & $7(6.4)$ & $13(10.7)$ \\
\hline
\end{tabular}

Values represent $N(\%)$. NCG, no-contact control group; BIG, brief intervention group; CCG, contact control group. All questions pertain to the previous 12-month period. 
